\title{
O RACIONAL E O RAZOÁVEL NO DISCURSO JURÍDICO
}

LAURO AUGUSTO MOREIRA MAIA 


\section{O RACIONAL E O RAZOÁVEL NO DISCURSO JURÍDICO}

\section{Lauro Augusto Moreira Maia'}

\section{RESUMO:}

Este trabalho investiga as noções do racional e do razoável e os seus usos no discurso jurídico pragmático.

Palavras-chave: lógica do racional e lógica do razoável. Discurso e uso jurídico.

\section{ABSTRACT:}

This research investigate the rational and reasonable notions and their uses in the pragmatic legal discourse.

Keywords: rational logic e reasonable logic. Disourse and juridical use.

1 Juiz Titular da 5 a Vara Cível da Comarca de Palmas-TO. Autor do livro 'Os novos paradigmas do Direito Civil. Mestre em Direito Constitucional pela Universidade de Coimbra - Portugal. Doutorando em Direito Público da Universidade de Coimbra - Portugal. Email: lauro@tjto.jus.br 


\section{INTRODUÇÃO}

“- Meu pai, é verdade que Deus tudo pode?

- É verdade, sim, meu filho. Deus tudo pode.

- E se Deus quiser morrer?

- Bem, aí você me obriga a recompor a idéia. Deus tudo pode, é certo, menos deixar de tudo poder. Logo, Deus tem que permanecer vivo, porque somente assim, Ele vai prosseguir sendo Aquele que tudo pode.” (BRITTO, Carlos Ayres. Teoria da Constituição. Rio de Janeiro:Forense, 2003. p. 5.).

O diálogo acima, entre pai e filho, evidencia como uma aparente pergunta simples e uma resposta certa e clara podem engendrar perplexidades. Mostra ainda que essas perplexidades são enfrentadas de modo diverso da categoria de discurso que o produziu.

Entre a primeira e a segunda respostas não há contradição, como uma leitura apressada poderia detectar. Há sim uma forma diversa de responder decorrente da circunstância do rompimento lógico do diálogo. Se estamos falando de Deus, como criador do universo e do Homem, Deus como motor imóvel, a categoria morte sequer pode ser concebida. Deus não é simplesmente um ser vivo. Contudo, por razões circunscritas ao diálogo era preciso pensar uma resposta para além (ou diversa) de uma certa concepção de Deus.

Em alguma medida a questão pode, como metáfora, ilustrar de forma inaugural uma distinção que pretendemos desenhar entre lógica do racional e lógica do razoável. 


\section{A LÓGICA DO RACIONAL}

A ciência construiu um longo percurso desde a antiguidade até o século XXI. Foi, contudo, no século XVII que ela desenhou para si um "estatuto" próprio e assumiu uma posição privilegiada no amplo domínio do saber humano.

$\mathrm{O}$ estatuto do científico se separa definitivamente das demais formas de conhecimento, inclusive da filosofia, principalmente porque entre o objeto de seu estudo e o observador se interpõe um método demasiado exigente por meio do qual será obtido um conhecimento verdadeiro, seja porque submetido ao teste da experiência e experimentação, seja porque deduzido de forma correta das premissas lógicas que o possibilitaram.

$\mathrm{O}$ método em questão e que aqui nos interessa de modo especial é o racional. Ele exige um rigor conceitual das formas que assimila e, ainda, coerência na sistematização. Em sua manifestação mais autêntica está intimamente associado à métodos apriorísticos, como a dedução silogística.

A lógica do racional atende às exigências de poder de previsibilidade, certeza e direcionalidade, requisitos fundamentais para o enquadramento do conhecimento sob esse rótulo.

De acordo com Jean Ladrière ${ }^{2}$, a idéia geral de racionalidade capta três significações:

2 LADRIĖRE, Jean. O racional e o razoável. In MORIN, Edgar. O desafio do século XXI. Religar os conhecimentos. Tradução de Ana Rabaça. Lisboa: Instituto Piaget, 2001, p. 441442. 
a) Racionalidade de um sujeito pensante - aqui está em questão a exigência de uma postura (do sujeito) que vai operar rigorosa e constantemente sob o "controle de uma atenção crítica";

b) Racionalidade como características da realidade que incluem também o próprio sujeito, as coisas e o mesmo o mundo;

c) Racionalidade que se manifesta como um "domínio objetivo" - um domínio que embora criado pelo homem, desliga-se da sua origem e passa a funcionar de forma autônoma, abstraída da sua gênese subjetiva. São os modelos teóricos criados pelo homem.

As três significações se completam e estão fortemente interligadas. De alguma forma se pode, resumindo, dizer que, a primeira significação coloca o acento agudo sobre o sujeito pensante, a segunda sobre o mundo enquanto objeto inteligível e a terceira sobre os métodos que se posicionam entre o sujeito e o objeto.

É interessante que o próprio Ladrière aponta como paradigma do racional "a máquina informática" 3. Essa máquina realiza operações complexas em um espaço de tempo finito, produzindo assim efetividade. Há uma certa objetivação na tarefa do computador na medida em que oferece respostas. operando por meio dos seus próprios recursos, aparentando.

3 LADRIÈRE, Jean. O racional e o razoável. In MORIN, Edgar. O desafio do sécul⿵ XXI. Religar os conhecimentos. Tradução de Ana Rabaça. Lisboa: Instituto Piaget, 2001, p. 444: "A máquina informática fornece, aqui, o modelo mais ilustrativo do objecto construído, com efeito, é concebida para realizar operações efectivas, de resto seja qual for a complexidade que apresentarem e fornece mesmo tal como outrora Turing demonstrou, a representação mai: concreta da ideia do processo efectivo". 
portanto, o funcionamento de um autômato.

Exatamente essa idéia de autonomia vai permitir o seu funcionamento (sua operação), abstraído das intenções que estiveram na sua gênese, separando (na verdade aparentando separar), assim, seu processamento do ato humano criador que se encontra na sua origem. Algo que trabalha por si mesmo independentemente da ação humana que está na sua raiz.

Esse "autômato" é "capaz não apenas de realizar tarefas determinadas conforme a instruções dadas, mas de ter em contas a experiência, de adquirir novos conhecimentos, de compreender os seus próprios erros, de aperfeiçoar, nesta base, as suas próprias instruções operativas, de aumentar a eficácia, de elevar as qualidades de suas actuações, em suma de tematizar o seu próprio comportamento, de acordo com uma espécie de reflexividade que está no princípio de reforço de autonomia. O sistema racional oferece, assim, à própria acção novos recursos e torna-lhe acessível novos campos onde se investir." ${ }^{4}$

É próprio do racional, assim, oferecer um conhecimento exato, certo ${ }^{5}$, verdadeiro. O êxito dessa conquista é possibilitado por meio de instrumentos formais a exemplo do silogismo. A autoridade de suas conclusões é alheia a quaisquer argumentos substanciais e vai depender da correta mobilização dos

4 LADRIĖRE, Jean. Op. Cit., p. 445.

5 Toulmin nesse aspecto afirma que "as questões ligadas à consistência formal e da prova dedutiva vieram, assim, a ter um prestígio especial e alcançaram um tipo de certeza que outros tipos de opiniões nunca puderam reivindicar". (TOULMIN, Stephen. Como a razão perdeu seu equilibrio. In: SANTOS, Boaventura de Souza (Org). Conhecimento prudente para uma vida decente. Um discurso sobre as ciências revisitado. Porto: Edições Afrontamento, 2003, p. 255). 
mecanismos formais que tem a seu dispor.

Esse mecanismo de processamento é completamente indiferente na sua operação a qualquer ato de vontade. O racional realiza uma redução da complexidade por meio de uma obediência canônica a mecanismos procedimentais. As etapas formais do raciocínio não apenas guiam a construção do conhecimento, mas constrangem o produto final de tal forma que entre o questionamento e a solução final existe uma relação necessária, sob pena de erro. Isso quer dizer, em primeiro lugar, que a conclusão, de alguma forma, já está nas premissas e, em último lugar, que, a princípio, só existe uma solução correta para cada questionamento. ${ }^{6}$

É comumente associado à lógica do racional "os clássicos princípios da identidade (cada objeto é idêntico a si mesmo), da contradição (se um de dois juízos contraditórios é verdadeiro o outro é necessariamente falso), do terceiro excluído (se um de dois juízos reciprocamente opostos é falso o outro é necessariamente verdadeiro) e da razão suficiente (para ser verdadeiro cada juízo carece de um fundamento bastante)." 7

O racional traduzido para a práxis jurídica vai implicar em

6 Atienza, interpretando Perelman, lembra que "a lógica formal se move no terreno da necessidade. Um raciocínio lógico-dedutivo, ou demonstrativo, implica - como vimos - que a passagem das premissas para a conclusão é necessária. Se as premissas são verdadeiras então a conclusão também será, necessariamente."(ATIENZA, Manuel. As razões do direito. Teorias da argumentação jurídica. Perelman, Viehweg, Alexy e outros. Tradução de Maria Cristina Guimarães Cupertino. $3^{\mathrm{a}}$ edição. São Paulo: Landy, 2003, p. 61). Destaques nossos.

7 BRONZE, Fernando José. A metodonomologia (Para além da argumentação). Boletim da Faculdade de Direito. Coleção STVDIA IVRIDICA n ${ }^{\circ}$ 90. Separata de ARS IUDICANDI. Estudos em homenagem ao professor Doutor António Castanheira Neves. Coimbra: Coimbra editora. p. 350 
categorias "centradas na norma... axiomaticamente estruturadas em simétricas combinações binárias (obrigatório-não obrigatório, permitido-não permitido, proibido-não proibido, preterível-não preterível) indiferentes ao que (atento o in fieri dinamizador da juridicidade) ainda não é mas deve vir a ser obrigatório-não obrigatório, permitido-não permitido..., e manifesta-se, por isso, pouco adequada "para lidar [metodonomologicamente] com [a novidade, a especialidade, a irrepetibilidade e a irredutibilidade - numa palavra que tudo sintetiza: com a oneness - de] casos... particulares e concretos." 8

Se o fundamental está assentado em um procedimento ou uso rigoroso de mecanismos formais, o racional é também uma lógica individualista e solitária tendo em vista que para o seu êxito é dispensável qualquer noção de diálogo.

Ocorre que tudo isso nos induz a questionar alguns pontos desse modelo:

a) A idéia de direcionalidade e a produção de um conhecimento abstraído de uma vontade conflita com a necessidade humana de livre arbítrio e da retomada da idéia moderna de um homem como construtor do seu próprio destino?;

b) Esse modelo racional estaria em condições de fornecer respostas para problemas e angústias humanos no contexto de uma sociedade cada vez mais plural e complexa?;

c) Como atuar diante de problemas socialmente abrangentes e onde todos se sentem de alguma forma atingidos

8 BRONZE, Fernando José. Op.cit. p. 350-351. 
com as suas soluções, a exemplo da questão do aborto, eutanásia, questões ambientais etc.?;

d) $\mathrm{O}$ que fazer quando o racional ou os modelos tradicionais que representam esse "racional", geram perplexidades lógicas?

\section{O RAZOÁVEL}

O racional é um poderoso artifício da criação humana, porém limitado e falível. Incapaz de se adequar ao sentido demiúrgico do ser humano. A complexidade da experiência humana não pode sempre ser captada ou explicada em termos quantitativos ou conceituais, mas compreendida em termos qualitativos.

O caminhar expresso pela humanidade exige mais que a idéia de efetividade. A construção de uma sociedade autenticamente civilizada onde o rosto do "outro" revela a compreensão de si mesmo, somente se constrói a partir de uma afetividade que, como se sabe, não pode ser encontrada pura e simplesmente numa lógica racional.

Os comandos lógicos e suas projeções no direito não são propriamente imorais. São amorais. Pois as formas e condicionamentos previamente estabelecidos no programa ou nas premissas são indiferentes à qualquer finalidade a ser atingida, mormente se essa finalidade inclui valores e essa indiferença faz todo sentido quando se trata de resolver angústias humanas.

Asolução razoável é ainda uma solução da razão. É, porém, 
uma razão diversa do racional. De certo modo é mais rica que o racional em sentido estrito porque inclui elementos substanciais e é "constituída não por premissas, mas por argumentos" e também é "modelada... mundanal e mundividencialmente" 9 .

Oferece um saber mais limitado, sobretudo quando se busca um controle mais eficaz para determinados fatos.

A autoridade da lógica do razoável não advém de qualquer mecanismo formal, mas de argumentos substanciais que mobilizam valores. ${ }^{10}$ Por isso aqui simplesmente não existe a idéia de certeza. O razoável oferece no máximo um conhecimento provável. Toulmin, a propósito, lembrou que "os argumentos substanciais são historicamente contextualizados e baseiam-se nas provas da experiência: o máximo que eles podem pretender é colocar uma conclusão para além de uma dúvida razoável e estabelecer a presunção mais forte possível" 11

Quando se diz que essa lógica não oferece certeza ou verdade, não se deve pensar que o razoável conviva com soluções arbitrárias. Apesar de não trabalhar ao modo de uma operação

9 BRONZE, Fernando José. A metodonomologia (Para além da argumentação). Boletim da Faculdade de Direito. Coleção STVDIA IVRIDICA n 90. Separata de ARS IUDICANDI. Estudos em homenagem ao professor Doutor António Castanheira Neves. Coimbra: Coimbra editora. p. 353 .

10 A propósito Perelman enfatiza que "contrariamente à demonstração de um teorema de geometria, que estabelece de uma vez para sempre um laço lógico entre verdades especulativas, a argumentação do discurso epidíctico propõe-se a aumentar a intensidade da adesão a certos valores de que não se dúvida, talvez quando se consideram isoladamente, mas que poderiam, não obstante, não prevalecer diante de outros valores que viriam a entrar em conflito com eles." (PERELMAN, Chaim. Ética e direito. tradução de João Duarte. Lisboa: Instituto Piaget, 2006, p. 60).

11 TOULMIN, Stephen. Como a razão perdeu seu equilíbrio. In: SANTOS, Boaventura de Souza (Org). Conhecimento prudente para uma vida decente. Um discurso sobre as ciências revisitado. Porto: Edições Afrontamento, 2003, p. 259. 
ou planejamento, o razoável dispõe da interpretação exatamente com o objetivo de controlar a profusão de sentidos ${ }^{12}$. Nem todas as respostas são satisfatórias e o arbitrário é inaceitável.

Qualidades como universalização, generalização e atemporalidade não fazem parte da noção do razoável, pois esta noção se deixa influenciar e leva em conta as contingências da própria "experiência cotidiana" e por isso está referido a um "onde e quando, um aqui e agora ou um ali e então." ${ }^{13}$ Daí ser apropriada a lição de Ladrière no sentido de que "a visão do razoável é a compreensão na concreção dos condicionamentos, daquilo que está implicado, em relação às pressões que exercem e às possibilidades que propõem, na importância de um mundo de acordo com a liberdade." 14

Perelman também constatou isso quando lembrou que " uma lei de 7 de abril de 1922, na Bélgica, diversamente do que entendeu o Supremo Tribunal de Justiça em 1889, autorizou as mulheres ao exercício da advocacia. Assim, "o que era evidente em 1889 se tinha tornado irrazoável trinta anos mais tarde." 15

O racional, como afirmado, não deixa de, em alguma

12 "A operação inscreve-se no espaço definido por uma combinatória. A interpretação, por sua vez, parte de um dado fixo, mas não se pode deduzi-la, nem fixar seus limites antes dela ter espalhado todos os seus comentários. É virtual e virtualmente infinita. A interpretação é para a dotação de sentido o que a criação era para a invenção das formas." (LÉVY, Pierre. A máquina universo. Criação, cognição e cultura informática. Tradução de Bruno Charles Magne. Porto Alegre: Editora Artes Médicas Sul LTDA, 1998, p. 54).

13 TOULMIN, Stephen. Como a razão perdeu seu equilíbrio. In: SANTOS, Boaventura de Souza (Org). Conhecimento prudente para uma vida decente. Um discurso sobre as ciências revisitado. Porto: Edições Afrontamento, 2003, p. 256.

14 LADRIĖRE, Jean. P. 455. Destaques nossos.

15 PERELMAN, Chaim. Ética e direito. tradução de João Duarte. Lisboa: Instituto Piaget, 2006, P. 388. 
medida, expressar uma razão egológica, ensimesmada, no sentido de que evoca a idéia de um pesquisador que na sua solidão e isolamento revela uma descoberta. O razoável é sempre construído em contextos nos quais a presença do outro é pelo menos pressuposta, já que a solução deverá ser aceitável. Por isso, a noção de "auditório" é absolutamente essencial na teoria de Perelman, que lembrava: "não basta falar ou escrever, ainda é preciso ser ouvido, ser lido." 16

É certo que o razoável acomoda-se com mais propriedade não numa razão monológica, mas numa razão dialógica, mas o diálogo que aqui se expressa representa uma busca do consenso, não a sua imposição. É que o diálogo autêntico não conduz obrigatoriamente a um consenso. Como explica Francis Jacques $^{17}$ "le dialogue n'est pas forcément consensuel, il est aussi le lieu ou l'on voit grandir lês vrais désaccords, mais non sans que l'on parvienne à s'entendre sur le dèsaccord même. (...) L'essentiel est que chacun puísse former l'idée d'um accord au moin possible sur lequel s'enlève le desaccord. C'est aussi la seule façon d'aboutir à um vrai dissentiment qui ne repose pas sur um malentendu. D'ailleurs, le plaisir Du dialogue, qui est sans égal à mês yeux, est moi celui du consensus que dês fécondations incessantes et de la probité dans le contrôle mutuel de la pensée".

Descartes, figura a quem se pode atribuir o nascimento do

16 PERELMAN, Chaim. e OLBRECHTS-TITECA, Lucie. Tratado da argumentação. tradução de João Duarte. Lisboa: Instituto Piaget, 2006, p. 25.

17 JACQUES, Francis. Argumentation et stratégies discursives. In LAMPEREUR, A. L'argumentation. Mardaga, Liège, 1991, p. 165. 
racionalismo moderno e, portanto, associado à lógica do racional, destacava com certa insistência o caráter necessariamente solitário e individual do conhecimento. Ele admitia que existisse “... diversas opiniões sobre a mesma matéria, a serem sustentadas por gente douta", contudo, sem jamais cogitar que "pudesse haver mais que uma única opinião verdadeira, reputava de quase falso o que era apenas verossímil." ${ }^{18}$ Esse era o alicerce de seu método.

O filósofo dizia ainda que "já que se fala de assuntos humanos, creio que se Esparta foi outrora tão florescente, isso não se ficou devendo à perfeição de cada uma de suas leis em particular... mas porque, não tendo sido inventadas por um só, elas tendiam todas ao mesmo fim. E assim eu pensava que a ciência dos livros, ao menos daqueles cujas razões não são 'senão prováveis e que não são suscetíveis de demonstração, tendo sido ordenada pouco a pouco, com as opiniões de várias e diversas pessoas, não se encontra tão próxima da verdade como os raciocínios simples que um homem de bom senso pode fazer naturalmente acerca das coisas que se lhe deparam." ${ }^{19}$ Dai que para o seu modelo lógico "a pluralidade de voz não é prova bastante para as verdades pouco propícias à descoberta porque é mais verossímil que tenham sido descobertas por um só homem do que por um povo" 20

18 DESCARTES. Discurso do método. Tradução e notas de Pinharanda Gomes. $5^{a}$ edição, Lisboa: Guimarães, 2010, p. 18. Destaques nossos.

19 DESCARTES. Discurso do método. Tradução e notas de Pinharanda Gomes. $5^{\text {a }}$ edição, Lisboa: Guimarães, 2010, p. 24-25. Destaques nossos. 
A segunda parte do seu discurso do método, aliás, é bem sintomática desse aspecto que importa ressaltar:

Por não encontrar convívio social algum que me distraísse, e, também, felizmente, por não ter qualquer desejos ou paixões que me perturbassem, ficava o dia inteiro fechado sozinho num quarto bem aquecido, onde dispunha de todo o tempo para me entreter com os meus pensamentos... ${ }^{21}$

\section{UMA TENTATIVA DE SÍNTESE}

Nesse momento será apresentada a visão de alguns dos principais autores que se dedicaram a diferenciar a lógica do racional da lógica do razoável, com a finalidade de oferecer uma síntese da questão e habilitar nossa investigação para uma segunda fase, já não mais implicativa, mas aplicativa. ${ }^{22}$

edição, Lisboa: Guimarães, 2010, p. 30. Destaques nossos.

21 DESCARTES.Discurso do método; As paixões da alma e Meditaç̃̃es. Coleção Os Pensadores. São Paulo: Nova Cultural. 1999, p. 43.

22 Os conceitos de aplicação e implicação não se confundem. Nesse particular, $\mathrm{A}$ Professora Maria José Esteves de Vasconcelos esclarece: "Por falar em implicações parece oportuno destacar a fundamental diferença entre aplicações e implicações. Uma teoria pode ter aplicações, regras ou princípios, dela derivados, para a prática. Por exemplo, as aplicações da teoria construtivista de Piaget, em situações de ensino e aprendizagem. E, por outro lado, uma teoria pode também ser tomada como epistemologia. Por exemplo, quando se concebeu a familia como um sistema análogo a um sistema cibernético, a Teoria Cibernética foi tomada, pelos estudiosos da família, como uma epistemologia: um conjunto de crenças sobre um funcionamento cibernético do sistema familiar. Por isso, desde minha dissertação de mestrado tenho procurado explicitar as bases epistemológicas da terapia familiar, ou seja, as implicações da epistemologia cibernética para essas práticas clínicas. Entretanto, é preciso ficar claro que uma epistemologia, como tal, não pode ter aplicações, mas apenas implicações. Não se trata aqui de uma escolha entre termos equivalentes. Implicações são consequêências necessárias e inevitáveis de se ter adotado uma determinada epistemologia. Por exemplo, certas crenças e certos valores dos pais sobre educação de filhos implicarão necessariamente que apliquem castigos rigorosos aos filhos. Assim também uma epistemologia sistêmica terá fortes e inevitáveis implicações para as práticas profissionais na educação, na abordagem da saúde, das empresas, da ecologia, das politicas assistenciais, no direito, nas relações internacionais". (VASCONCELLOS, Maria José 
A doutrina apresentada não tem a pretensão de resumir todo o pensamento dos autores citados quanto à questão, mas oferece recortes de seus textos que condensam substancialmente a parte nuclear do que interessa a essa pesquisa.

Manuel Atienza destacou bem a diferença entre a perspectiva racional e a perspectiva razoável. Quanto à primeira apontou que:

uma decisión jurídica está racionalmente justificada si y solo si: 1) respeta los princípios de consistência (en el sentido de que no comete errores de tipo lógico), de universalidad y coherencia; 2) no elude La utilización como premissa de alguna fonte del Derecho Del caráter vinculante; 3) no desconoce a existência de hechos probados em La forma debida, y 4) no utiliza como elementos decisivos de La fundamentación criterios éticos, políticos, etc., no previstos especificamente (aunque pudieram estarlo genericamente) por el ordenamento jurídico. ${ }^{23}$

Quanto à segunda:

una decisión jurídica es razonable si y sólo si: 1) se toma en situaciones en que no se podría o no seria aceptable adoptar uma decisión que respete los critérios da racionalidad formal; 2) logra un equilíbrio óptimo entre as distintas exigencias que se plantean en la decisión, y 3 ) obtiene um máximo de consenso. ${ }^{24}$

Esteves de. Pensamento sistêmico: o novo paradigma da ciência. 4. Ed. Campinas-SP: Papirus, 2005).

23 ATIENZA, Manuel. Tras la justicia. Barcelona: Editirial Ariel, 2003, p. 174.

24 ATIENZA, Manuel. Tras la justicia. Barcelona: Editirial Ariel, 2003, p. 175.

Revista Esmat, Palmas, Ano 3, n 3, pag. 75 a 119 - jan/dez 2011 
Perelman ${ }^{25}$ sintetiza parcialmente a diferença entre as duas lógicas:

Enquanto em direito as idéias de razão e racionalidade foram associadas a um modelo divino, por um lado, e à lógica e à técnica eficaz, por outro, as idéias de razoável e o seu oposto, o irrazoável estão ligadas às reacções do meio social e à sua evolução. Enquanto as noções de 'razão' e 'racionalidade' se ligam a critérios bem conhecidos da tradição filosófica, tais como as idéias de verdade, coerência e de eficácia, o razoável e o irrazoável estão ligados a uma margem de apreciação admissível e ao que, excedendo os limites permitidos, parece socialmente inaceitável.

Aulis Aarnio, numa abordagem diferente da de Perelman, "entende que a planificação racional é uma condição necessária para a preservação da sociedade. Quando impera a imprevisibilidade, a sociedade se dissolve na anarquia, que, por sua vez está dissociada de toda uma fundamentação justa e jurídica" ${ }^{26}$, daí recusar decisões arbitrárias, mas, para além disso, Arnio também propõe a idéia de aceitabilidade, obtida discursivamente. $\mathrm{O}$ autor ainda aponta que "para ser aceitável, tem que responder ao conhecimento e ao sistema de valores da comunidade jurídica." ${ }^{27} \mathrm{O}$ Autor ainda formulou o princípio

\footnotetext{
25 PERELMAN, Chaim. Ética e direito. tradução de João Duarte. Lisboa: Instituto Piaget, 2006, P. 392.

26 Aarnio, Aulis. Lo racional como razonable. Un tratado sobre la justificación jurídica. Madri: Centro de Estudios Constitucionales, 1991, p. 26.

27 Aarnio, Aulis. Lo racional como razonable. Un tratado sobre la justificación jurídica. Madri: Centro de Estudios Constitucionales, 1991, p.248.
} 
regulativo (R) que descreve nesses termos: "a dogmática jurídica deve intentar lograr aquelas interpretações jurídicas que puderem contar com o apoio da maioria em uma comunidade jurídica que pensa racionalmente" 28

Luis Recaséns Siches ${ }^{29}$ apontou que a lógica do razoável tem as seguintes características:

$\left.1^{\circ}\right)$ está limitada o circunscrita, está condicionada y está influida, por la realidad concreta del mundo en que opera; $2^{\circ}$ ) está impregnada de valoraciones, esto es, de critérios estimativos o axiológicos. Adviértase que esa dimensión es por completo ajena a la lógica formal, o a qualquier teoria de inferência;

$\left.3^{\circ}\right)$ tales valoraciones son concretas, es decir, están referidas a uma determinada situación humana real, a uma cierta constelación social y en conseqüência, deben tomar em cuenta todas las possibilidades y todas las limitaciones reales;

$\left.4^{o}\right)$ las valoraciones constituyen a base de apoyo para la formulación de los objetivos, esto es, para el estabelecimento de las finalidades;

$5^{\circ}$ ) pero la formulación de objetivos o estabelecimento de fines no solo se apoya sobre valoraciones, sino que además está condicionado por las possibilidades que le ofrezca la realidad humana social concreta;

$\left.6^{\circ}\right)$ a lógica do razonable está regida por razones de congruência o de adequación:

a) Entre la realidad social y los valores, es decir: cuáles Sean los valores apropiados para la ordenación de uma determinada realidad social;

28 Aarnio, Aulis. Lo racional como razonable. Un tratado sobre la justificación jurídica. Madri: Centro de Estudios Constitucionales, 1991, p. 286.

29 SICHES, Luis Recaséns. Introducción al estúdio del derecho. $16^{\mathrm{a}}$ edição. México: Editorial Porrua, 2009, p. 258-259. 
b) Entre los valores y los fines o objetivos, esto es, cuáles Sean os objetivos valiosos;

c) Entre los objetivos y la realidad social, esto es: cuáles sean los propósitos de posible y conveniente realización;

d) Entre los fines u objetivos y los médios, em cuanto a la adequación de los médios para los fines;

e) Entre los fines y los médios respecto de la correción ética de los médios. Se trata de evitar la caida abismal em la perversa máxima de que el fin justifica los médios, máxima de intrínseca maldad, porque cuando se trata de servir um fin bueno com medios malos el fin pierde la bondad, contagiándose de los médios;

f) Entre fins y los médios, em lo que se refiere a la eficacia dos médios.

$\left.7^{\circ}\right)$ A lógica do razonable está orientada por las enseñanzas extraidas de la experiência de la vida humana y de la experiência histórica, esto es, de la experiência individual $y$ de la experiencia social - presente y pasada -, y se desenvuelve instruida por esa experiência.

Também se pode colher da jurisprudência uma contribuição para a temática. Trata-se do voto do ministro do Supremo Tribunal Federal, Carlos Britto, no julgamento do Habeas Corpus $n^{\circ}$ 97.256-RS. No caso concreto estava em discussão a constitucionalidade do art. 44 da lei 11.343 de 2006. A lei em causa impedia a conversão da pena privativa de liberdade em restritiva de direitos. A Corte declarou a lei inconstitucional, tendo em vista que ela não permitia a adequada aplicação do princípio da individualização da pena, retirando do juiz parcela insuprimível da discricionariedade judicial na busca da equilibrada modulação entre gravidade do crime e retribuição da pena. Em seu voto, o relator assinalou que: 
Daqui se deduz que a lei comum não tem a força de subtrair do juiz sentenciante o poder-dever de impor ao delinqüente que a ele, juiz, se afigurar como a expressão de um concreto balanceamento ou de uma empírica consideração (mandado de optimização, diria Ronald Dworkin) de circunstâncias objetivas com protagonizações subjetivas do fato-tipo. Implicando essa ponderação em concreto - porque não dizer? - a opção jurídico-positiva da prevalência do razoável sobre o racional. É que a pura racionalidade se dá nos colmos olímpicos da abstração mental, sempre ávida por trabalhar com categorias tão universais quanto atemporais, que são categorias válidas para toda e qualquer situação existencial. Diferentemente do juízo de razoabilidade que toma em conta o contexto ou as contigências das protagonizações humanas. Atenta à elementar consideração de que o Direito é feito para a concreta vida dos homens em sociedade, e o fato é que a concreta vida dos homens em sociedade escapa até mesmo a mais circunstanciada ou minudente descrição legislativa, regida que é, tal como na particularizada esfera dos fenômenos quânticos, pelos princípios da complementariedade e da incerteza - para lembrar a conhecida categorização de Heizemberg. Ou como no século V a.C. sentenciava Heráclito: 'o ser das coisas é o movimento' (e as coisas ditas humanas não fogem à regra). Por isso é que só o impermanente é que é permanente; somente o inconstante é que é constante, porque tudo muda incessatemente, menos a incessante mudança. 


\section{DA NOÇÃO DO RAZOÁVEL NO DIREITO}

A noção de razão sempre "desempenhou um papel não menosprezável no direito" ${ }^{30}$, como lembrou Perelman, mas a partir do pós-segunda Guerra ${ }^{31}$ a teoria geral do direito passar a contemplar em seus métodos, agora explicitamente, a lógica do razoável.

Surgem assim trabalhos expressamente assumindo essa perspectiva, a exemplo de Luis Recasèns Siches, o próprio Perelman, Teodhor Vievheg, Aulis Aarnio entre outros.

Não é correto dizer que "a razoabilidade, enquanto tal, é uma noção completamente vazia" ${ }^{32}$. O seu largo uso na construção de várias soluções jurídicas indicia fortemente que se trata de importante e substancial idéia. Quase todas as noções que temos das coisas requerem uma contextualização para a sua compreensão. Daí que até seja possível acusar o razoável de indeterminado, nunca, porém, de indeterminável.

Manuel Atienza não foi inteiramente preciso em sua

30 PERELMAN, Chaim. Ética e direito. tradução de João Duarte, Lisboa: Instituto Piaget, 2002, p. 384.

31 Gilbert Hottois, a propósito, lembra que "o desenvolvimento das lógicas não clássicas caracteriza-se pela diversidade e actualidade. Enquanto a lógica formal se cristaliza, no que toca ao essencial, no fim do século XIX e início do século XX, o desenvolvimento de lógicas não clássicas não se inicia antes dos anos 1920-1930 e só após a Segunda Grande Guerra se desenvolve verdadeiramente"(HOTTOIS, Gilbert. Pensar a lógica. Uma introdução técnica e teórica à filosofia da lógica e da linguagem. Tradução de Miguel Mascarenhas. Lisboa: Instituto Piaget, 2004, p. 105).

32 BUSTAMANTE, Thomas da Rosa. A Razoabilidade na dogmática jurídica contemporânea: em busca de um mapa semântico. In NOVELINO, Marcelo. Leituras complementares de direito constitucional. Teoria da constituição. Salvador-Bahia: JusPodivm, 2009, p. 208. 
crítica quando afirmou que "o pecado capital de Perelman é a falta de clareza conceitual, do ponto de vista prático, esse pecado é o conservadorismo ideológico... é o caso dos conceitos de pluralismo, razoabilidade e imparcialidade..." ${ }^{33}$

O engano de Atienza consiste no fato de que a noção de razoável ou de razoabilidade não se deixa aprisionar por qualquer conceito. Razoabilidade não é uma grandeza matemática, física ou um edifício teórico, nem composto por elementos eternos e universais. Neil MacCormick foi mais feliz em sua descrição quando falou em razoabilidade como uma noção de conteúdo variável $^{34}$, embora, para ser mais preciso, num primeiro momento, o que se pode dizer é que "a razoabilidade não pode ser capturada em termos conceituais." 35

Ladrière, a propósito, destaca muito apropriadamente ' que "a ação do razoável não é a realização de um plano, é a solicitação daquilo que está presente como sempre para vir e como entrincheirado no lugar do inatribuível da ordem dos fins. Assim, comporta de si, uma inevitável indeterminação, que apela, por si só, para um princípio de determinação como

33 ATIENZA, Manuel. As razões do direito. Teorias da argumentação jurídica. Perelman, Viehweg, Alexy, MacCormick e outros. Tradução de Maria Cristina Guimarães Cupertino. $3^{\text {a }}$ edição. São Paulo: Landy, 2003, p. 82.

MAcCORMICK, Neil. On reasonableness. In PERELMAN, Chaim. et VANDER ELST, Raymond (Orgs). Les notions a contenu variable en droit. Bruxelles, E. Bruylant, 1984, p. 131. jurídica contemporânea: em busca de um mapa semântico. In NOVELINO, Marcelo. Leituras complementares de direito constitucional. Teoria da constituição. Salvador-Bahia: JusPodivm, 2009, p. 211. 
mediação necessária da sua própria eficácia." ${ }^{36}$

Essa exigência de rigor conceitual lembra muito o positivismo normativista, que além de tentar constituir um modelo jurídico absolutamente indiferente a valores, tencionava desenhar uma ciência pura das normas, completamente dessubstantivada. ${ }^{37}$ Esse positivismo "centrou seu método jurídico na aplicação (lógico-dedutiva) da legislação." ${ }^{38}$ Não tardou para ser reconhecido como insuficiente. A experiência do nacional-socialismo deixaria evidente a necessidade, no pósguerra, de repensar um proposta diferente para o direito.

E esse é um bom momento para iniciar uma maior compreensão da emergência de uma nova forma de pensar o direito e sua realização concreta.

Assim, importa agora questionar qual o lugar do razoável na vida do direito, vale dizer: como compreendê-lo no discurso jurídico? Antes, porém, importa destacar algumas diferenças com outras figuras semelhantes.

Cabe, desde logo, lembrar que parte da doutrina confunde

36 LADRIÈRE, Jean. O racional e o razoável. In MORIN, Edgar. O desafio do século XXI. Religar os conhecimentos. Tradução de Ana Rabaça. Lisboa: Instituto Piaget, 2001, p. 452.

37 Nesse sentido, Kelsen afirmou categoricamente que "Uma norma juridica não vale porque tem um determinado conteúdo, quer dizer, porque o seu conteúdo pode ser deduzido pela via de um raciocínio lógico de uma norma fundamental pressuposta, mas porque é criada por uma forma determinada - em última análise, por uma forma fixada por uma norma fundamental pressuposta... Por isso, todo e qualquer conteúdo pode ser Direito. Não há qualquer conduta humana que, como tal, por força do seu conteúdo, esteja excluida de ser conteúdo de uma norma juridica." (KELSEN, Hans. Teoria pura do direito. $7^{\mathrm{a}}$ Edição. São Paulo: Martins Fontes, 2006.p. 221).

38 BRONZE, Fernando José. A metodonomologia (Para além da argumentação). Boletim da Faculdade de Direito. Coleção STVDIA IVRIDICA nº 90. Separata de ARS IUDICANDI. Estudos em homenagem ao professor Doutor António Castanheira Neves. Coimbra: Coimbra editora. p. 361 . 
a razoabilidade com equidade.

O padrão aqui tomado como referência é a idéia de equidade no sentido descrito por Aristóteles, que assim a resumiu:

O fundamento para tal função rectificadora resulta de, embora toda lei seja universal, haver, contudo, casos a respeito dos quais não é possível enunciar de modo correcto um princípio universal. Ora, nos casos em que é possível enunciar um princípio universal, mas aos quais não é possível aplicá-lo na sua totalidade de modo correcto, a lei tem em consideração apenas o que se passa o mais das vezes, não ignorando, com isso, a margem para o erro, mas não deixando, contudo, de actuar menos correctamente. $\mathrm{O}$ erro não reside na lei nem no legislador, mas na natureza da coisa: isso é simplesmente a matéria do que está exposto as ações humanas. Quando a lei enuncia um princípio universal e se verifica resultarem casos que vão contra essa universalidade, nessa altura está certo que se rectifique o defeito, isto é, que se rectifique o que o legislador deixou escapar e a respeito do que, por se pronunciar de modo absoluto, terá errado. É isso o que o próprio legislador determinaria se presenciasse o caso ou viesse a tomar conhecimento da situação, rectificando, assim, a lei, a partir das situações concretas que de cada vez se constituem. ${ }^{39}$

Todavia, o texto é bastante elucidativo e claro, razão pela qual fica patente a diferença das duas noções.

A lógica do razoável aplicada ao direito não se limita a essa "justiça corretiva" do texto legislado. Primeiro porque

39 ARISTÓTELES. Ética a Nicómaco. Tradução, prefácio e notas de António de Castro Caeiro. Lisboa: Quetzal Editores, 2009, p. 141. 
a necessidade de correção pode surgir do próprio equívoco concreto do aplicador da lei; segundo porque em situações mais complexas (ou nalguns casos difíceis, hard cases) o julgador sequer dispõe de material legislativo a ser aplicado.

A equidade é tão-só uma pequena parte da noção mais abrangente do razoável, já que esse se espraia por situações mais numerosas, distintas e complexas.

Uma segunda distinção oportuna a ser feita remete ao pensamento que enquadra a razoabilidade como princípio.

Em que pese uma certa (e talvez forte) intimidade entre as duas noções, o razoável não é um princípio.

É certo que a noção do razoável apresenta algumas semelhanças com os princípios, mormente quando recordamos a maior abertura e indeterminação de ambos. Mas o princípio aceita um jogo conflitual que, num caso concreto, pode ser preterido por outro de maior peso numa relação concreta. Isso não se passa com a lógica do razoável, tendo em vista que jamais poderá ser desconsiderada, para o êxito de qualquer princípio. É que "o irrazoável não pode ser admitido em direito." 40

Aidéia de razoabilidadenãotem um sentidoimediatamente normativo. Ela não determina um comportamento específico a qualquer pessoa, não veicula mandamentos.

A razoabilidade não deve ser vista como norma, mas como um postulado pressuposto para a aplicação de normas e também calibrador na concreta realização de um princípio $^{41}$.

40 PERELMAN, Chaim. Ética e direito. p 385. 
Nesse sentido, ela pode ser vista como uma metanorma à disposição da metodologia para presidir as soluções jurídicas ali onde o racional e a mobilização dos seus modelos apriorísticos, na prática jurídica, revelaram-se insuficientes.

Por postulado entende-se aqui, em conformidade com a descrição de Humberto Ávila, as condições essenciais necessárias para a interpretação de qualquer objeto cultural e, no caso, dos problemas jurídicos (e não apenas normas). Um postulado normativo, como a razoabilidade, traduz a noção de norma imediatamente metódica responsável pela criação de critérios de aplicação de outras normas e, por isso, é também chamado de norma de segundo grau ou metanorma. ${ }^{42}$

\section{AS APLICAÇÕES DO RAZOÁVEL}

A lógica do razoável enquanto busca de uma solução adequada para as questões jurídicas vai ser exigida essencialmente em três situações:

a) Em caso de insuficiência epistêmica do racional;

Acórdão 509/2002, Processo 768/2002, caso no qual se discutiu a questão da parcial supressão do RMG - Rendimento Mínimo Garantido, pelo menos aos jovens entre 18 e 25 anos de idade. $\mathrm{Na}$ fundamentação constou que "O princípio da igualdade, entendido como limite objectivo da discricionariedade legislativa, não veda à lei a realização de distinções. Proíbe-lhe, antes, a adopção de medidas que estabeleçam distinções discriminatórias, ou seja, desigualdades de tratamento materialmente infundadas, sem qualquer fundamento razoável (vernünftiger Grund) ou sem qualquer justificação objectiva e racional. Numa expressão sintética, o princípio da igualdade, enquanto princípio vinculativo da lei, traduz- se na ideia geral de proibição do arbítrio (Willkürverbot).»" E ainda: "Significa isto que a distinção etária efectuadana norma questionada só será admissível se não for arbitrária, ou seja, se tiver uma justificação razoável."

42 ÁVILA, Humberto. Teoría de los Principios. Tradução de Laura Criado Sanchez. Madri: Marcial Pons, 2011, p. 111. 
b) Em caso de insuficiência axiológica do racional; e

c) Em caso de insuficiência lógica do racional.

No primeiro caso - que chamo de insuficiência epistêmica - o direito enfrenta uma situação que para a sua solução se exige essencialmente um exame de uma questão de fato. $\mathrm{O}$ direito necessita aqui responder se determinado fato ocorreu ou não. O nível é predominantemente o da constatação, embora possa haver algum espaço à valoração.

Quando os modelos lógicos, especialmente o subsuntivo ou silogístico, não se mostram satisfatórios para a solução do problema resta recorrer à lógica do razoável.

Uma narrativa apresentada por Toulmim pode ajudar na compreensão do tema. Trata-se da história do Conde e do Abade, com origem no século XVIII:

Duas senhoras idosas estão a receber convidados e o primeiro a chegar é uma pessoa importante que por acaso é um Conde. Os três discutem o confessionário e o Conde comenta: 'bem, minhas Senhoras, eu posso dizer-vos isso: fui o primeiro penitente do Abade'. Ele sai pouco depois e chega o Abade em pessoa. A conversa continua e, muito instado, o Abade pigarreia e diz: 'sem violar o meu dever de sigilo, deixem-me dizer-vos, minhas Senhoras, simplesmente isso: 'o meu primeiro penitente foi um assassino""43

Recorrendo ao silogismo não resta dúvida de que a

43 TOULMIN, Stephen. Como a razão perdeu seu equilibrio. In: SANTOS, Boaventura de Souza (Org). Conhecimento prudente para uma vida decente. Um discurso sobre as ciências revisitado. Porto: Edições Afrontamento, 2003, p. 256. 
conclusão que se impõe é: "o Conde é um assassino". Mas antes é legitimo indagar se essa resposta não é demasiado simplista para ser considerada adequada. E a resposta é que a solução é insuficiente e isso porque deixa de levar em consideração uma série de circunstâncias que podem alterar as impressões iniciais e conduzir a uma conclusão diversa.

Nesse caso seria apropriado questionar - como fez Toulmim - se "...tanto o Conde quanto o Abade estão a dizer a verdade" ou ainda se "qualquer um deles (ou ambos) possa estar a vangloriar-se." 44

Já na segunda situação - insuficiência axiológica - a resposta que a dimensão problematizante põe está intimamente vinculada a uma concepção de mundo que o homem na sua autonomia, perspectiva de construção de seu destino e no "exercício da sua liberdade (e responsabilidade) pretende ver realizado.

Aqui na insuficiência axiológica já não está em jogo um exame de uma situação de fato. $\mathrm{O}$ direito, nessa perspectiva, não pede uma constatação. Levam-se em consideração, prioritariamente, o grau civilizador que a sociedade quer (e pode) alcançar, os rumos que pretende tomar, os valores que deseja ver triunfar, ainda que apenas provisoriamente, numa dinâmica de uma sociedade complexa e conflituosa. Nesse particular, a idéia de valor é absolutamente importante. Se na primeira hipótese

44 TOULMIN, Stephen. Como a razão perdeu seu equilíbrio. In: SANTOS, Boaventura de Souza (Org). Conhecimento prudente para uma vida decente. Um discurso sobre as ciências revisitado. Porto: Edições Afrontamento, 2003, p. 256-257. 
estava em causa um juízo de fato, nessa segunda concepção está em causa um juízo de valor. É nesse momento que o direito se apresenta mais assumidamente como habitando o seu mundo, que é o mundo do dever-ser.

Exemplo disso foi oferecido pelo Superior Tribunal de Justiça que permitiu o levantamento do FGTS (fundo de garantia por tempo de serviço) para fins de tratamento de HIV (SIDA) mesmo sabendo que essa situação não estava prevista na lei de regência. ${ }^{45}$

Outra questão que pode servir de exemplo é o instituto da indignidade na herança. No Brasil os casos estão assim catalogados no código:

Art. 1.814. São excluídos da sucessão os herdeiros ou legatários:

I - que houverem sido autores, co-autores ou partícipes de homicídio doloso, ou tentativa deste, contra a pessoa de cuja sucessão se tratar, seu cônjuge, companheiro, ascendente ou descendente;

II - que houverem acusado caluniosamente em juizo o autor da herança ou incorrerem em crime contra a sua honra, ou de seu cônjuge ou companheiro;

III - que, por violência ou meios fraudulentos, inibirem ou obstarem o autor da herança de dispor livremente de seus bens por ato de última vontade.

Em Portugal a disciplina é quase idêntica: 
(Incapacidade por indignidade)

Carecem de capacidade sucessória, por motivo de indignidade:

a) $\mathrm{O}$ condenado como autor ou cúmplice de homicídio doloso, ainda

que não consumado, contra o autor da sucessão ou contra o seu cônjuge,descendente, ascendente, adoptante ou adoptado;

b) O condenado por denúncia caluniosa ou falso testemunho contra as mesmas pessoas, relativamente a crime a que corresponda pena de prisão superior a dois anos, qualquer que seja a sua natureza;

c) $\mathrm{O}$ que por meio de dolo ou coacção induziu o autor da sucessão a fazer, revogar ou modificar o testamento, ou disso o impediu;

d) O que dolosamente subtraíu, ocultou, inutilizou, falsificou ou suprimiu o testamento, antes ou depois da morte do autor da sucessão,

ou se aproveitou de algum desses factos.

De certa forma, ambas as situações (Código Civil Português e Brasileiro) podem ser resumidas em atentados: a) contra a vida; b) contra a honra; e c) atentado contra a liberdade de dispor, todos cometidos contra o de cujus ou contra aquelas pessoas indicadas na lei, todas elas por sua proximidade com o autor da herança.

Praticamente a unanimidade dos autores apontam que o texto tem uma finalidade ética. O professor Caio Mário da Silva Pereira aponta que o instituto tem "um fundamento ético" cuja finalidade é evitar que "venha alguém extrair vantagem ao patrimônio de pessoa a quem o ofendeu." ${ }^{46}$

PEREIRA, Caio Mário da Silva. Instituições de direito civil. Direito das sucessões. 
Entretanto, a doutrina brasileira e portuguesa majoritariamente defendem que os casos apontados na lei como causa de indignidade são taxativos e numerus clausus ${ }^{47}$, não se admitindo que por analogia seja possível criar novas situações, até porque a exclusão da herança é uma pena. ${ }^{48}$

Ocorre que essa concepção fechada, exaustiva e necessariamente deduzida de uma subsunção rigorosa pode desvirtuar completamente o "fundamento ético" do próprio instituto, consagrando mesmo uma medida de total desprezo ao mundo dos valores. ${ }^{49}$ Imagine-se, apenas por exemplo, um filho que atinge intencional e vigorosamente o pai, praticando o crime de lesão corporal de natureza grave, comprometendo seriamente a qualidade de vida deste.

No modelo subsuntivo a situação não constituiria causa de indignidade e então a disposição, com sua finalidade ética, iria consagrar, no exemplo dado, uma situação de verdadeira repulsa moral. A lógica do racional nesse caso conduz a um resultado axiologicamente insuficiente.

Vol. VI. Revista e atualizada por Carlos Roberto Barbosa Moreira. 15a edição. Forense: Rio de Janeiro. 2005, p. 37.

47 Entendendo pela taxatividade e enumeração axaustiva dos casos: (REsp 1102360/ RJ, Rel. Ministro MASSAMI UYEDA, TERCEIRA TURMA, julgado em 09/02/2010, DJe 01/07/2010 e Apelação Cível N ${ }^{\circ} 70003186897$, Sétima Câmara Cível, Tribunal de Justiça do RS, Relator: Luiz Felipe Brasil Santos, Julgado em 27/02/2002).

48 Tenho fortes dúvidas se a pena criminal e a civil devam obedecer a um mesmo estatuto.

49 Aqui cabe reafirmar o que Recaséns Siches havia aludido sobre a lógica do racional: " $6^{\circ}$ ) a lógica do razonable está regida por razones de congruência o de adequación: (...) e) Entre los fines y los médios respecto de la correción ética de los médios. Se trata de evitar la caída abismal em la perversa máxima de que el fin justifica los médios, máxima de intrínseca maldad, porque cuando se trata de servir um fin bueno com medios malos el fin pierde la bondad, contagiándose de los médios;" 
Um precedente do Tribunal da Relação de Guimarães, em Portugal, soube resolver um caso de indignidade, aplicando o art. 2034 de modo a realizar valores:

$1^{\circ}$ - Numa concepção normativo-pessoal, seguida pela jurisprudência e doutrina jurídico-penais portuguesa, a honra é vista como um bem jurídico complexo que inclui, quer o valor pessoal ou interior de cada indivíduo, radicado na sua dignidade (honra interna), quer a própria reputação ou consideração exterior (honra externa).

$2^{\circ}$ - Neste conceito abrangente de honra cabe, seguramente, todos os valores que se prendem com a "moral sexual" de cada pessoa e com os "sentimentos gerais da moralidade sexual", valores estes que estão na base da incriminação dos crimes sexuais, designadamente do crime de violação p. e p. pelos arts. $201^{\circ}$ e $208^{\circ}, n^{\circ} 1$. al a) e $n^{\circ} 3$ do Código Penal de 1982, pelo que não se vê razão para deixar de fazer subsumir a conduta apurada do réu na causa de indignidade prevista na alínea b) do citado art. $2034^{\circ}$ do C. Civil, por analogia com esta previsão, em conformidade com o disposto no art. $11^{\circ}, \mathrm{n}^{\circ} 1$ do C. Civil.

$3^{\circ}-\mathrm{O}$ art. $2034^{\circ}$, al b) do C. Civil tem de ser objecto de aplicação analógica, por forma a nele se poder integrar os condenados pela prática de outros crimes de ofensa à honra do autor da sucessão desde que sejam mais graves do que aqueles que o próprio legislador nele previu expressamente ou de idêntica gravidade.

$4^{\circ}$ - O regime de indignidade contido no art. $2034^{\circ}$ do C. Civil, é aplicável a todas as espécies de sucessão.

$5^{\circ}$ - É, assim, de considerar como indigno o comportamento do réu, que violou a autora da sucessão, sua filha menor, que engravidou-a e obrigou-a a abortar aos quinze anos de idade, impondo-se, por isso, afastá-lo da respectiva sucessão nos termos do disposto no art. $2034^{\circ}$, al. b) do C. 


\section{Civil.50}

A última situação é a que denominamos de insuficiência lógica e, nessa hipótese, o razoável assume a função de corrigir perplexidades a que às vezes está sujeito a concreta realização do direito.

Essa situação não convoca essencialmente valores, mas é solicitada para corrigir resultados absurdos, despidos do coeficiente mínimo de coerência e aceitabilidade. Não que inexista qualquer dimensão valorativa, mas o que sobretudo se apresenta é a necessidade de evitar soluções de perplexidade lógica.

Importante insistir que a situação de cabal incoerência não surge apenas na opção estática da dimensão textual apresentada pelo legislador, mas pode ser fruto de decisões judiciais e nesse caso é caudalosa a jurisprudência, desde situações na qual o juiz aplicou percentuais absurdos na fixação de honorários advocatícios até quando arbitrou o valor de danos morais em patamares evidentemente elevados.

Um caso é paradigmático dessa terceira hipótese: lei do Estado do Amazonas criou um adicional de férias inclusive para aposentados. O Supremo Tribunal Federal declarou a lei inconstitucional, considerando irrazoável que aqueles que sequer trabalhem recebam a vantagem.

A ementa do julgado está assim exposta:

50 Processo 2612/08-1. Relator: Rosa Tching. Data do acórdão: 22/01/2009. Apelação julgada procedente por unanimidade. 
AÇÃO DIRETA DE INCONSTITUCIONALIDADE LEI ESTADUAL QUE CONCEDE GRATIFICAÇÃO DE FERIAS (1/3 DA REMUNERAÇÃO) A SERVIDORES INATIVOS - VANTAGEM PECUNIÁRIA IRRAZOÁVEL E DESTITUIDA DE CAUSA - LIMINAR DEFERIDA. A norma legal, que concede a servidor inativo gratificação de férias correspondente a um terço $(1 / 3)$ do valor da remuneração mensal, ofende o critério da razoabilidade que atua, enquanto projeção concretizadora da cláusula do "substantive due process of law", como insuperável limitação ao poder normativo do Estado. Incide o legislador comum em desvio ético-jurídico, quando concede a agentes estatais determinada vantagem pecuniária cuja razão de ser se revela absolutamente destituída de causa.(ADI 1158 MC, Relator (a): Min. CELSO DE MELLO, TRIBUNAL PLENO, julgado em 19/12/1994, DJ 26-05-1995 PP-15154 EMENT VOL-01788-01 PP-00051)

Vale destacar parte importante do voto do relator:

Isso significa, dentro da perspectiva da extensão da teoria do desvio de poder ao plano das atividades legislativas do Estado, que este não dispõe de competência para legislar ilimitadamente, de forma imoderada e irresponsável, gerando, com o seu comportamento institucional, situações normativas de absoluta distorção e, até mesmo, de subversão dos fins que regem a atividade estatal.

Nesse último aspecto, o razoável é largamente identificado na jurisprudência:

PROCESSO CIVIL - EMBARGOS DE DIVERGENNCIA - HONORÁRIOS DE ADVOGADO - ESTIPULAÇÃO QUE ENVOLVE MATÉRIA DE FATO.

Revista Esmat, Palmas, Ano 3, n 3, pag. 75 a 119 - jan/dez 2011 
1. O acórdão recorrido contém tese abstraída no sentido de questionar no especial não os critérios estabelecidos pelo juiz, mas a falta de critério que levou à fixação de honorários que extrapolaram a lógica do razoável, em situação inteiramente atípica.

2. Os acórdãos paradigmas, diferentemente, afirmam de forma peremptória que em recurso especial não se discutem os critérios que levaram as instâncias ordinárias a estipular o valor dos honorários, entendendo que essa revisão esbarra no óbice da súmula 7/STJ.

3. Dissídio não configurado.

4. Embargos de divergência não conhecidos.

(EAg 292.305/SP, Rel. Ministra ELIANA CALMON, CORTE ESPECIAL, julgado em 04/08/2004, DJ 14/11/2005, p. 174).

Indenização por dano moral. Valor da causa. Pedido certo. Art. 258 do Código de Processo Civil.

1. A fixação de um valor absurdo, fora da realidade, sem pertinência com os autos, ademais de agredir a lógica do razoável, viola o art.258 do Código de Processo Civil, base sobre a qual fincou-se o julgado recorrido para admitir o valor indicado pelo autor.

2. Recurso especial conhecido e provido.

(REsp 167.475/SP, Rel. Ministro CARLOS ALBERTO MENEZES DIREITO, TERCEIRA TURMA, julgado em $16 / 03 / 1999$, DJ 31/05/1999, p. 144)

ADMINISTRATIVO - DESAPROPRIAÇÃO INDIRETA - JUROS COMPENSATORIOS.

TERMO INICIAL - DECLARAÇÃO DE UTILIDADE PÚBLICA.

I - NA DESAPROPRIAÇÃO INDIRETA, OS JUROS COMPENSATÓRIOS INCIDEM - EM CONJUNTO COM OS MORATÓRIOS - ATÉ O PAGAMENTO INTEGRAL DA INDENIZAÇÃO.

II - QUEM SE ORIENTA PELA JURISPRUDÊNCIA 
DEVE TER EM VISTA, SEMPRE, A LÓGICA DO RAZOÁVEL.

III - SE O PROPRIETÁRIO DEMOROU TRINTA ANOS, PARA RECLAMAR INDENIZAÇÃO POR DESAPROPRIAÇÃOINDIRETA,ÉRAZOÁVELQUESE ADOTE COMO TERMO INICIAL, PARA CONTAGEM DOS JUROS COMPENSATÓRIOS, A DATA EM QUE SE DECLAROU - COM DEZOITO ANOS DE ATRASO - A UTILIDADE PÚBLICA DO IMÓVEL. NÃO É SENSATO CONTRARIAR O PRECEITO TRADUZIDO NA PAREAMIA "DORMIENTIBUS NON SUCURRIT JUS”. (REsp 77.207/PR, Rel. Ministro HUMBERTO GOMES DE BARROS, PRIMEIRA TURMA, julgado em 10/06/1996, DJ 01/07/1996, p. 23996)

PROCESSO CIVIL. AÇÃO COMINATÓRIA. EXECUÇÃO. PENA PECUNIARIA. CPC, ARTS. 287, 644/645. ENRIQUECIMENTO INDEVIDO. LIMITAÇÃO. CC, ARTS. 92 E 924. HERMENÊUTICA. RECURSO INACOLHIDO.

I - O OBJETIVO BUSCADO PELO LEGISLADOR, AO PREVER A PENA PECUNIÁRIA NO ART. 644, CPC, FOI COAGIR O DEVEDOR A CUMPRIR A OBRIGAÇÃO ESPECÍFICA. TAL COAÇÃO, NO ENTANTO, SEM EMBARGO DE EQUIPARAR-SE ÀS "ASTREINTES" DO DIREITO FRANCÊS, NÃO PODE SERVIR DE JUSTIFICATIVA PARA O ENRIQUECIMENTO SEM CAUSA, QUE AO DIREITO REPUGNA.

II - É DA INDOLE DO SISTEMA PROCESSUAL QUE, INVIABILIZADA A EXECUÇÃO POR QUANTIA CERTA, RESPONDENDO O DEVEDOR POR PERDAS E DANOS RAZÃO PELA QUAL APLICÁVEIS OS PRINCIPIOS QUE NORTEIAM OS ARTS. 920 E 924 DO CODIGO CIVIL.[SIC]

III - A LEI, QUE DEVE SER ENTENDIDA EM TERMOS HÁBEIS E INTELIGENTES, DEVE IGUALMENTE MERECER DO JULGADOR INTERPRETAÇÃO 
SISTEMÁTICA E FUNDADA NA LÓGICA DO RAZOÁVEL, PENA = DE PRESTIGIAR-SE, EM ALGUNS CASOS, O ABSURDO JURIDICO. (REsp 13.416/RJ, Rel. Ministro SÁLVIO DE FIGUEIREDO TEIXEIRA, QUARTA TURMA, julgado em 17/03/1992, DJ 13/04/1992, p. 5001)

\section{UMA MANIFESTAÇÃO DO RACIONAL E DO RAZOÁVEL NA ORDEM JURÍDICA: O MODELO DE REGRAS E PRINCÍPIOS}

A razão sempre teve seu lugar fundamental no direito. $\mathrm{O}$ racional e o razoável sempre estiveram presentes na construção do direito, embora o último com menor intensidade até 1945 e com maior intensidade após esse período.

A partir da segunda metade do século passado, a reação em face da perplexidade e frustração com o positivismo normativista, conduz a idéia do razoável a ter um lugar de destaque na vida do direito. A noção de conteúdo e de moral devem ser consideradas seja na estática manifestação de um texto, seja na dinâmica realização como norma.

Mas a advertência é ainda importante: não houve uma eliminação do racional para dar lugar ao razoável. Diversamente disso, as duas noções coexistem e se manifestam no direito na sua medida e ao seu modo.

O racional tem o seu espaço e aplicação em muitos casos. Talvez muito mais do que se imagine. Assim, a título de simples exemplo pode-se lembrar que "a idade mínima para alguém se 
candidatar à presidente da República é de 35 anos (art. 14, § $3^{\circ}$, VI, a); ao completar 70 o servidor público será aposentado compulsoriamente (art. 40, $\S 1^{\circ}$, II); nenhum benefício da seguridade social poderá ser criado sem indicação da fonte de custeio (art. 195, $\S 5^{\circ}$ )" 51 .

Por isso é importante enfatizar que os dois modelos continuam sendo utilizados na solução de variados casos em direito a par, claro, de outros instrumentos existentes.

A teoria clássica vem apontando a adoção de um modelo aberto de regras e princípios.

As regras "são normas que são sempre satisfeitas ou não satisfeitas. Se uma regra vale, então, deve se fazer exatamente aquilo que ela exige; nem mais, nem menos" ${ }^{52}$ Dworkin ainda falava em normas aplicadas ao modo de um tudo ou nada (all "or nothing). Os conflitos entre regras são solucionáveis pela recurso a regras previamente existentes que tem a finalidade de por fim a essa antinomia (critério cronológico, especial etc.). A aplicação das regras é feita por meio da subsunção, donde exigir uma relação de harmônica semelhança entre fato e descrição normativa.

Em geral a doutrina tradicional reconhece que o "grau de generalidade das regras é relativamente baixo" ${ }^{53}$, pois tem uma estrutura semântica mais precisa, mais determinada, o que deixa

51 BARROSO, Luis Roberto. Curso de direito constitucional contemporâneo. Os conceitos fundamentais e a construção do novo modelo. São Paulo: saraiva. 2009, p. 205.

52 ALEXY, Robert. Teoria dos direitos fundamentais. Tradução de Virgílio Afonso da Silva. São Paulo: Malheiros, 2008, p. 91 
pouco espaço de mobilidade ao intérprete.

O modelo de regras, desse modo, atende mais à finalidade de segurança jurídica e se apresenta, assim, como uma evidente manifestação da lógica do racional aplicada ao direito.

Os princípios "são normas que ordenam que algo seja realizado na maior medida possível dentro das possibilidades jurídicas e fáticas existentes... são... mandamentos de otimização, que são caracterizados por poderem ser satisfeitos em graus variados e pelo fato de que a medida devida de sua satisfação não depende somente das possibilidades fáticas, mas também das possibilidades jurídicas." 54

Diferentemente das regras que tem um caráter definitivo, os princípios tem um caráter prima facie e, por isso, aqui, em caso de conflito não há regras formais a serem imediatamente mobilizadas para arbitrar uma solução. Nesse caso, são esgrimidos argumentos substanciais em favor e contra os princípios em tensão e logrará êxito aquele que diante do concreto problema apresentado for considerado de maior peso, ou o "mais pesado", isso "sem que, todavia, o [princípio] circunstancialmente preterido... [tenha] que ser (des-)qualificado como inválido" ${ }^{55}$, como acontece no caso das regras.

A maior indeterminação dos princípios termina por lhes

54 ALEXY, Robert. Teoria dos direitos fundamentais. Tradução de Virgilio Afonso da Silva. São Paulo: Malheiros, 2008, p. 90.

55 BRONZE, Fernando José. A metodonomologia entre a semelhança e a diferença. (Reflexão problematizante entre os pólos da radical matriz analógica do discurso jurídico). Boletim da Faculdade de Direito da Universidade de Coimbra. STVDIA IURIDICA, $\mathrm{n}^{\circ} 3$. Coimbra: Coimbra Editora, 1994, p. 503. 
possibilitar uma maior intimidade relacional com os valores. Isso levou Alexy a apontar que a diferença única entre princípios e valores é que os primeiros têm um caráter deontológico e os últimos têm um caráter axiológico. ${ }^{56}$

Os princípios, assim, atendem mais à finalidade de justiça e na concepção clássica atual são manifestações que atendem à lógica do razoável.

\section{CONCLUSÃO}

O nosso objetivo nessa investigação não foi esgotar a questão sobre a aplicação da lógica do racional e do razoável, a toda evidência.

O objetivo foi o de ajudar no debate acerca do tema e 'oferecer algumas linhas gerais de pensamento, sendo muito provável que ao final ainda surjam talvez muitas indagações. $\mathrm{E}$ se isso ocorreu essa pesquisa de alguma forma alcançou algum resultado positivo, afinal não são as respostas que movem o mundo e sim as perguntas.

Do que foi exposto é possível extrair algumas conclusões, sendo duas delas em nossa avaliação as mais importantes:

a) $\mathrm{O}$ racional estabelece uma ordem que manifesta o domínio de um mundo cujos objetos operam funcionalmente por meio dos seus próprios recursos, mobilizando os procedimentos ou programas previamente estabelecidos e que realizam sua

56 ALEXY, Robert. Teoria dos direitos fundamentais. Tradução de Virgílio Afonso da Silva. São Paulo: Malheiros, 2008, p. 153. 
tarefa à semelhança de um autômato. Contudo, essa autonomia vai implicar um funcionamento que atua de forma independente das intenções que presidiram a sua gênese radical e desse modo realiza operações com abstração de qualquer ato de vontade;

b) O razoável é a realização do retorno à origem mais radical do racional, a sua gênese, onde se encontra um ato humano criador, ato, portanto, de vontade e, por isso, ele retoma o horizonte dos fins e da solicitação de um mundo de acordo com a liberdade. Daí que o horizonte do razoável não possa ser explicado nem compreendido conceitualmente nem possibilite pura e simplesmente sua aplicação sob a forma de um princípio a uma situação determinada.

De forma complementar também se pode apontar outras conclusões:

c) Racional e razoável são, ambas, noções que integram a Razão;

d) A lógica do racional se pretende mais exata, mais definitiva, mais acabada, com limites mais bem desenhados. Os instrumentos postos à disposição desse modelo já estão previamente à disposição do intérprete. Pense-se nos além da dedução silogística, nos brocardos e máximas utilizados pelo operador do direito na busca de uma solução (A lei não contém palavras inúteis; a norma restritiva interpreta-se estritamente; onde a lei não distinguiu não cabe ao interprete distinguir etc.). É essa concepção que vai conduzir a disposições textuais fechadas e exaustivas;

e) A noção do razoável não tem a pretensão de certeza e 
pode ser convocada diante do apelo concreto de um problema que não pôde ser satisfatoriamente resolvido pelos métodos lógicos e tradicionais. Por essas razões, disposições legais taxativas e esgotantes tendem a não se acomodar adequadamente numa concepção da lógica do razoável;

f) A razoabilidade tem a oferecer não "a" decisão correta, nem mesmo a "única" decisão, mas a decisão mais aceitável sempre pensada em termos de um diálogo, ainda que hipotético, mas que não dispensa, em qualquer das soluções que aponta, um apoio ético;

g) O razoável não se confunde com princípio, nem com a idéia de equidade, mas funciona como um postulado que atua na realização de outras normas e como controle de validade das leis;

h) $\mathrm{O}$ direito se complementa com as duas noções (racional e razoável) que são ainda caras e necessárias para a correta solução dos problemas, até porque cada uma preenche uma finalidade especial reclamada pelo direito;

Nessas derradeiras linhas não é demais deixar uma pergunta a ser respondida: entramos já no século XXI e o homem ainda tem que enfrentar a fome, a pobreza e a desigualdade em todas as suas formas. Temos ou não que pensar num modelo para além do racional e razoável para resolver esses graves dilemas humanos? A solução para esses problemas reclama uma lógica ou, para além de qualquer lógica, uma vontade (diferente) que realmente atue? 


\section{REFERÊNCIAS BIBLIOGRÁFICAS}

AARNIO, Aulis. Lo racional como razonable. Un tratado sobre la justificación jurídica. Madri: Centro de Estudios Constitucionales, 1991.

ALEXY, Robert. Teoria dos direitos fundamentais. Tradução de Virgílio Afonso da Silva. São Paulo: Malheiros, 2008.

ARISTÓTELES. Ética a Nicómaco. Tradução, prefácio e notas de António de Castro Caeiro. Lisboa: Quetzal Editores, 2009.

ATIENZA, Manuel. As razões do direito. Teorias da argumentação jurídica. Perelman, Viehweg, Alexy, MacCormick e outros. Tradução de Maria Cristina Guimarães Cupertino. $3^{\text {a }}$ edição. São Paulo: Landy, 2003.

ATIENZA, Manuel. Tras la justicia. Barcelona: Editirial Ariel, 2003.

ÁVILA, Humberto. Teoría de los Principios. Tradução de Laura Criado Sanchez. Madri: Marcial Pons, 2011.

BARROSO, Luis Roberto. Curso de direito constitucional contemporâneo. Os conceitos fundamentais e a construção do novo modelo. São Paulo: saraiva. 2009. 
BRONZE, Fernando José. A metodonomologia entre a semelhança e a diferença. (Reflexão problematizante entre os pólos da radical matriz analógica do discurso jurídico). Boletim da Faculdade de Direito da Universidade de Coimbra. STVDIA IURIDICA, n 3. Coimbra: Coimbra Editora, 1994.

BRONZE, Fernando José. A metodonomologia (Para além da argumentação). Boletim da Faculdade de Direito. Coleção STVDIA IVRIDICA $\mathrm{n}^{\circ}$ 90. Separata de ARS IUDICANDI. Estudos em homenagem ao professor Doutor António Castanheira Neves. Coimbra: Coimbra editora.

BUSTAMANTE, Thomas da Rosa. A Razoabilidade na dogmática jurídica contemporânea: em busca de um mapa "semântico. In NOVELINO, Marcelo. Leituras complementares de direito constitucional. Teoria da constituição. Salvador-Bahia: JusPodivm, 2009.

DESCARTES. Discurso do método. Tradução e notas de Pinharanda Gomes. 5a edição, Lisboa: Guimarães, 2010.

HOTTOIS, Gilbert. Pensar a lógica. Uma introdução técnica e teórica à filosofia da lógica e da linguagem. Tradução de Miguel Mascarenhas. Lisboa: Instituto Piaget, 2004.

JACQUES, Francis. Argumentation et stratégies discursives. In LAMPEREUR, A. L'argumentation. Mardaga, Liège, 1991. 
KELSEN, Hans. Teoria pura do direito. $7^{\mathrm{a}}$ Edição. São Paulo: Martins Fontes, 2006.

LADRIÈRE, Jean. O racional e o razoável. In MORIN, Edgar. O desafio do século XXI. Religar os conhecimentos. Tradução de Ana Rabaça. Lisboa: Instituto Piaget, 2001.

LÉVY, Pierre. A máquina universo. Criação, cognição e cultura informática. Tradução de Bruno Charles Magne. Porto Alegre: Editora Artes Médicas Sul LTDA, 1998.

MACCORMICK, Neil. On reasonableness. In PERELMAN, Chaim. et VANDER ELST, Raymond (Orgs). Les notions a contenu variable en droit. Bruxelles, E. Bruylant, 1984.

PEREIRA, Caio Mário da Silva. Instituições de direito civil. Direito das sucessões. Vol. VI. Revista e atualizada por Carlos Roberto Barbosa Moreira. $15^{\text {a }}$ edição. Forense: Rio de Janeiro. 2005.

PERELMAN, Chaim. Ética e direito. Tradução de João Duarte. Lisboa: Instituto Piaget, 2006.

PERELMAN, Chaim. e OLBRECHTS-TITECA, Lucie. Tratado da argumentação. Tradução de João Duarte. Lisboa: Instituto Piaget, 2006. 
KELSEN, Hans. Teoria pura do direito. $7^{\mathrm{a}}$ Edição. São Paulo: Martins Fontes, 2006.

LADRIÈRE, Jean. O racional e o razoável. In MORIN, Edgar. $\mathrm{O}$ desafio do século XXI. Religar os conhecimentos. Tradução de Ana Rabaça. Lisboa: Instituto Piaget, 2001.

LÉVY, Pierre. A máquina universo. Criação, cognição e cultura informática. Tradução de Bruno Charles Magne. Porto Alegre: Editora Artes Médicas Sul LTDA, 1998.

MAcCORMICK, Neil. On reasonableness. In PERELMAN, Chaim. et VANDER ELST, Raymond (Orgs). Les notions a contenu variable en droit. Bruxelles, E. Bruylant, 1984.

PEREIRA, Caio Mário da Silva. Instituições de direito civil. Direito das sucessões. Vol. VI. Revista e atualizada por Carlos Roberto Barbosa Moreira. $15^{\mathrm{a}}$ edição. Forense: Rio de Janeiro. 2005.

PERELMAN, Chaim. Ética e direito. Tradução de João Duarte. Lisboa: Instituto Piaget, 2006.

PERELMAN, Chaim. e OLBRECHTS-TITECA, Lucie. Tratado da argumentação. Tradução de João Duarte. Lisboa: Instituto Piaget, 2006. 
SICHES, Luis Recaséns. Introducción al estúdio del derecho. $16^{\mathrm{a}}$ edição. México: Editorial Porrua, 2009.

TOULMIN, Stephen. Como a razão perdeu seu equilíbrio. In: SANTOS, Boaventura de Souza (Org). Conhecimento prudente para uma vida decente. Um discurso sobre as ciências revisitado. Porto: Edições Afrontamento, 2003. 
SICHES, Luis Recaséns. Introducción al estúdio del derecho. $16^{\text {a }}$ edição. México: Editorial Porrua, 2009.

TOULMIN, Stephen. Como a razão perdeu seu equilíbrio. In: SANTOS, Boaventura de Souza (Org). Conhecimento prudente para uma vida decente. Um discurso sobre as ciências revisitado. Porto: Edições Afrontamento, 2003. 